Running Head: Post Traumatic Stress and Gambling Motives

Examining Links between Post-Traumatic Stress and Gambling Motives:

The Role of Positive Gambling Expectancies

Joshua B. Grubbs ${ }^{\mathrm{a}}$, Heather Chapman ${ }^{\mathrm{b}}$, Lauren Milner ${ }^{\mathrm{c}}$, Ian A. Gutierrez ${ }^{\mathrm{b}, \mathrm{d}}$, and David F. \author{
Bradley $^{\mathrm{b}, \mathrm{e}}$

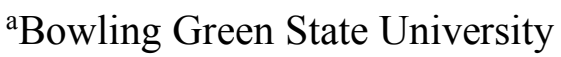 \\ ${ }^{\mathrm{b}}$ Louis Stokes Cleveland VA Medical Center \\ ${ }^{\mathrm{c}}$ Meridian Behavioral Health Services \\ ${ }^{\mathrm{d} U n i v e r s i t y ~ o f ~ C o n n e c t i c u t ~}$ \\ ${ }^{\text {e}}$ Case Western Reserve University
}

This is a preprint of the peer reviewed publication:

Grubbs, J., Chapman, H., Milner, L., Gutierrez, I., \& Bradley, D. F. (2018). Examining links between post-traumatic stress and gambling motives: The role of positive gambling expectancies. Psychology of Addictive Behaviors, Online First.

http://dx.doi.org/10.1037/adb0000399

Declaration of Interests: None.

Correspondence concerning this article should be addressed to Joshua B. Grubbs, Ph.D.,

Department of Psychology, Bowling Green State University, Bowling Green, OH, 43403.

Email: GrubbsJ@BGSU.edu 


\section{Post-Traumatic Stress and Gambling Motives: Examining the Role of Positive Gambling Expectancies}

Joshua B. Grubbs, Heather Chapman, Lauren Milner, Ian A. Gutierrez, and David F. Bradley

Problem gambling and gambling disorder $(G D)$ are associated with a range of mental health concerns that extend beyond gambling behaviors alone. Prior works have consistently linked gambling disorder with symptoms of post-traumatic stress disorder (PTSD), both cross-sectionally and over time. However, very little work has examined the specific relationships between these two disorders. The present work postulated that symptoms of PTSD are likely associated with unique beliefs about gambling behaviors and unique motivations to gamble. Using two samples - an inpatient sample of U.S. Armed Forces veterans $(N=332)$ seeking treatment for $G D$ and a web-sample of gambling adults $(N=589)$-we examined these ideas. Results from both samples indicated that symptoms of PTSD were related to positive gambling expectancies and coping motivations for gambling. Additionally, in both samples, positive gambling expectancies were associated with greater coping motivations for gambling. Structural equation models revealed that positive gambling expectancies were consistently associated with coping motivations for gambling. The findings indicate that symptoms of PTSD are likely associated with unique beliefs about and motivations for gambling behaviors. Given the high comorbidity between symptoms of PTSD and GD, these specific relationships are likely of clinical interest in populations seeking treatment for either PTSD or for problems with gambling behaviors.

Gambling Disorder (hereafter: GD) is the subject of hundreds of empirical inquiries (for reviews, see: Fauth-Bühler, Mann, \& Potenza, 2017; Goodie et al., 2013; Milosevic \& Ledgerwood, 2010) and a longstanding component of major diagnostic manuals for mental illness (Stinchfield et al., 2016). Yet, despite the prevalence of research on GD (relative to other behavioral addictions; see: Grant, Potenza, Weinstein, \& Gorelick, 2010), a robust scientific account of the course and causes of GD is still a necessary focus of research. One domain in which this is particularly apparent is the comorbidity of GD with post-traumatic stress symptoms and posttraumatic stress disorder (PTSD). For example, Many studies have found a high comorbidity between PTSD and GD (e.g., Biddle, Hawthorne, Forbes, \& Coman, 2005; Chou \& Afifi, 2011; Ledgerwood \& Milosevic, 2015); however, only a few have examined how PTSD relates to specific cognitive or behavioral characteristics of GD (e.g., Ledgerwood \& Milosevic, 2015; Najavits, 2010; Najavits, Meyer, Johnson, \& Korn, 2011). The present work examined these issues more directly, with an explicit focus on the role that cognitive beliefs about gambling might play in accounting for the relationship between PTSD and problematic gambling.

\section{Gambling Disorder and Post Traumatic Stress Disorder}

GD is an addictive disorder characterized by preoccupation, escalation, and failed attempts at regulation or restriction, despite life altering consequences associated with the behavior (FauthBühler et al., 2017; Petry, Blanco, Jin, \& Grant, 2014; Reilly \& Smith, 2013). Like other addictive disorders, GD is often comorbid with a range of other psychiatric conditions and mental illnesses (Petry, 2005), including PTSD (Chou \& Afifi, 2011). In nationally representative samples, people with GD report comorbid PTSD at rates much higher than the general population (Chou \& Afifi, 2011; Kessler et al., 2008). Among epidemiological studies of homeless populations, those with disordered gambling behaviors were more likely than those without to also have diagnosable PTSD (Nower, Eyrich-Garg, Pollio, \& North, 2015). Similarly, a number of smaller-scale studies of people with GD have found rates of PTSD to be higher than rates in the general population (e.g., 19\%, Ledgerwood \& Milosevic, 2015; 34\%, Ledgerwood \& Petry, 2006; $41 \%$, Taylor \& Sharpe, 2008; $24 \%$, Toneatto \& Pillai, 2016; 17\%, Westermeyer, Canive, Garrard, Thuras, \& Thompson, 2005)

Moving beyond cross-sectional associations alone, longitudinal analyses also corroborate the links between PTSD and GD. In a U.S. nationally representative sample, the presence of subclinical GD at baseline predicted slightly increased odds of PTSD three years later, and the presence of clinically diagnosable GD predicted substantially increased odds of PTSD three years later (Parhami, Mojtabai, Rosenthal, Afifi, \& Fong, 2014). Similarly, twin cohort studies (Scherrer, Xian, et al., 2007) reveal 
that children who are the victims of child abuse or physical attacks are more likely to develop later problems with gambling. Further analyses of that same sample also found that the presence of a PTSD diagnosis seems to be a substantial risk factor for developing later problems with gambling (Scherrer, Slutske, et al., 2007). In short, across a variety of samples, there is a clear association between GD and PTSD. However, beyond a basic link between the two disorders, there has been relatively little research examining the mechanisms that might account for the high comorbidity between these two diagnoses.

\section{Post-Traumatic Stress Disorder and Gambling Motives}

Numerous prior works have noted links between PTSD and various addictive behavior patterns, with some specifically noting that people may engage in addictive behaviors to cope with distress associated with PTSD (Ouimette \& Brown, 2003). More specifically, addictive behaviors often provide a means of relief from distress and temporary elevations in mood that may be particularly appealing or reinforcing to individuals with PTSD (Brady \& Sinha, 2005; Khantzian, 1997). Some prior works have similarly linked PTSD to such motivations for gambling behaviors. In a community sample of individuals with GD, those with confirmed PTSD demonstrated greater coping motivations for gambling, or gambling as a means to regulate mood and reduce negative affect (Ledgerwood \& Milosevic, 2015). This is consistent with prior research linking comorbid PTSD and GD to greater distress overall and a greater desire to reduce distress (Najavits, 2010; Najavits et al., 2011). However, in this community sample (Ledgerwood \& Milosevic, 2015), gamblers with PTSD were also more prone to negative emotion in general (e.g., greater trait negative emotionality). In short, gamblers with PTSD demonstrated more negative emotionality and a greater desire to use gambling to manage such emotions. Such a confluence of factors suggests that individuals with comorbid GD and PTSD are often at specific risk for severe psychological and behavioral problems (Najavits, 2010; Najavits et al., 2011; Najavits, Sullivan, Schmitz, Weiss, \& Lee, 2004). Consistent with prior works describing emotionally vulnerable gamblers (Ledgerwood \& Petry, 2010; Milosevic \& Ledgerwood, 2010), gamblers with PTSD and GD seem to be particularly distressed and motivated to use gambling to relieve such distress. As such, there is a need for greater understanding of how PTSD, and possibly even sub-clinical levels of posttraumatic stress more generally (e.g., symptoms of
PTSD that do not meet diagnostic criteria for PTSD), might be related to coping motivations for gambling among gamblers.

\section{Post-Traumatic Stress and Gambling Related Cognitions}

Research has only begun to examine possible factors or mechanisms that might explain the high comorbidity of PTSD and GD. However, specific beliefs regarding gambling behaviors, often referred to as gambling-related cognitions (Emond \& Marmurek, 2010; Miller \& Currie, 2008; Raylu \& Oei, 2004), are a strong candidate as such factors. Gambling-related cognitions take many forms, such as clear cognitive distortions (e.g., illusions of control, beliefs in predictability of chance, perceived inability to stop, interpretative biases; Raylu \& Oei, 2004). However, some may not represent distorted cognitions, per se, but rather beliefs about gambling that could potentially be problematic, particularly for vulnerable populations. Specifically, when considering the role of gambling-related cognitions as they relate to the use of gambling to cope, a particular set of cognitions of interest are positive gambling expectancies, or beliefs that gambling will improve one's mood, affect, or well-being (Raylu \& Oei, 2004).

Intuitively, the belief that gambling will improve affect or mood should be associated with the use of gambling to manage negative emotions or experiences. Although there is often a conceptual distinction (Stewart \& Zack, 2008) between gambling for enhancement motives (i.e., for excitement or thrill) and gambling for coping motives (i.e., to improve mood or reduce emotional distress), gambling to reduce distress implies a belief that gambling will help one feel better or enhance one's mood. Indeed, there is some research linking such expectancies to coping motivations for gambling (Mathieu, Barrault, Brunault, \& Varescon, 2017). This past research concluded that coping motives for gambling are related to various cognitive distortions or beliefs about gambling, including positive expectancies. However, this prior research was only conducted among poker-playing men and did not examine women, gamblers using other games, or gamblers with GD. In short, although there is evidence of links between positive gambling expectancies and motivations to use gambling as a coping mechanism, these links have not been extensively studied in exclusively GD populations, in gamblers in general, or in gamblers who might be particularly prone to negative affect (e.g., those with PTSD or exhibiting symptoms of PTSD). 
Additionally, the role of such expectancies in attenuating the link between symptoms of PTSD and coping motivations for gambling has not been examined.

\section{The Present Study}

Based on the above information, the present work was designed to examine how PTSD may be linked to specific gambling-related cognitions and motives. The objectives of the present study were threefold:

1. We examined whether the links between PTSD/subclinical post-traumatic stress (e.g., symptoms of PTSD below the threshold of PTSD) and use of gambling to cope with negative affect (e.g., coping motivations for gambling) extended to samples with severe GD and to a largely non-clinical sample of gamblers (i.e., not necessarily experiencing problems associated with gambling).

2. We explored whether the links between symptoms of PTSD and coping motivations for gambling were partially accounted for by positive gambling expectancies.

3. Finally, given previously discussed links between PTSD, GD, and greater dispositional negative affect (Ledgerwood \& Milosevic, 2015), we tested whether these motivations were best accounted for by an overall propensity toward negative affect (e.g., neuroticism).

Given prior findings illustrating a link between GD, PTSD, and the use of gambling to cope with negative emotions, we anticipated finding similar patterns in the present work. Specifically, we expected that post-traumatic stress among gamblers (both clinically diagnosable PTSD and sub-clinical manifestations of PTSD symptoms) would be associated with greater use of gambling to cope with negative affect and that these links would persist above and beyond the influence of a general propensity toward negative affect (i.e., trait neuroticism). Moving beyond prior findings, we also expected symptoms of PTSD to be related to positive gambling expectancies (e.g., optimistic gambling cognitions), as such cognitions are conceptually consistent with the use of gambling to cope with negative emotions. Finally, we expect to find that these expectancies would cross-sectionally attenuate

\footnotetext{
${ }^{1}$ Although not the primary focus of our proposed study, we also assessed rates of comorbid substance use disorders available in obtained data. In Sample 1,
}

the link between symptoms of PTSD and coping motivations for gambling.

\section{Participants and Procedure}

Participants for our first sample were veterans of the U.S. Armed Forces seeking treatment in a five-week residential program for Gambling Disorder $\left(N=332,80 \%\right.$ men, $\left.M_{\text {age }}=53.5, S D=11.5\right)$ between the years 2010-2015. All participants had been screened for GD prior to admission to the program and, consequently, had a diagnosis of GD. Participants were predominantly White/Caucasian (69\%), followed by African-American/Black (21\%), Native American/American Indian (3\%), Asian/Pacific Islander (3\%), Hispanic/Latino (2\%), and other (2\%). Participants completed all study measures as part of a routine intake assessment questionnaire administered upon admission into the residential treatment program. ${ }^{1}$

For our second sample, adults $(N=1,137)$ were recruited from Amazon's Mechanical Turk (MTurk) online labor marketplace via the TurkPrime data acquisition platform (Litman, Robinson, \& Abberbock, 2017). Participants completed this survey in June of 2017. MTurk is used extensively in social science research and is useful for studying clinically relevant phenomena (Chandler \& Shapiro, 2016; Shapiro, Chandler, \& Mueller, 2013), including GD behaviors (Kim \& Hodgins, 2017).

Participants interested in the survey were presented with the following screening item: "In the past year, have you ever gambled? This includes any of the following: purchasing scratch-offs, purchasing lottery tickets, playing the stock market, betting on sports, going to casinos, playing keno, playing slots or video poker, playing games for money, or playing fantasy sports for money." This item was presented in a list of 7 other items (e.g., "In your entire life, have you ever viewed pornography online? This includes looking at sexually explicit videos or pictures online." and "Over the course of your lifetime, have you used or abused any illegal substances (e.g., marijuana, cocaine, bath salts, LSD, ecstasy)?"). The purpose of this list format was to obscure the specific screening criteria of interest from participants. Only those who endorsed gambling activity in the past 12 months (inclusion rate $=77 \%$; $N=881$ ) completed all measures. This rate is slightly higher than national estimates of gambling behavior (e.g., 60\%; Potenza, Maciejewski, \& Mazure, 2006),

our inpatient sample of treatment-seeking veterans with confirmed GD, comorbid SUD/AUDs were common (prevalence rate $=33.6 \%$ ). 
although it is roughly comparable to national rates for lifetime prevalence of gambling behaviors (e.g., 78\%; Toneatto \& Pillai, 2016). Among these, only those who reported the experience of trauma (either directly experiencing such traumas or witnessing directly; see inclusion criteria below) were included in analyses. This left us with a final sample size of 589 (inclusion rate $=86 \% ; 43 \%$ men, $M_{\text {age }}=36.1, S D$ $=11.0$ ).

The survey took approximately 45 minutes to complete and participants were paid $\$ 7.00$ for successfully completing the survey. Several check items were included in the survey (e.g., "please select item 3" or "What time is it currently? Because not all participants read questions thoroughly, please do not type the current time. Instead, please type 12:00"). Participants who missed two or more attention check items were omitted from analyses $(n=6)$. Similarly, one participant with a clearly indiscriminate response style (e.g., answering all "Strongly Disagree" to a number of heterogenous measures) was also removed from analyses.

Participants ${ }^{2}$ in our final sample were predominantly White/Caucasian (77\%), followed by African-American/Black (12\%), Native

American/American Indian (2\%), Asian/Pacific Islander (8\%), Hispanic/Latino (9\%), and other/prefer-not-to-say (2\%). As participants could select multiple racial/ethnic affiliations, percentages may exceed $100 \%$.

\section{Measures}

Descriptive statistics for all included measures, including alpha-reliability coefficients, are included in Table 1.

Gambling severity. To assess severity of gambling symptoms, participants in both samples completed the South Oaks Gambling Screen (Lesieur $\&$ Blume, 1987). This 21 -item measure asks participants to respond to items related to disorder gambling behaviors. Responses consistent with GD are assigned a value of 1 ; responses inconsistent with GD were assigned a value of 0 . Responses were summed.

Gambling related cognitions. Positive expectancies for gambling were assessed via the Gambling Expectancies subscale of the Gambling-

\footnotetext{
${ }^{2}$ In Sample 2, our online convenience sample of gambling adults, reported relatively low levels of other addictive behavior patterns (e.g., mean score on the Drug Abuse Screening Test $=3.13, S D=2.66 ; 92 \% \leq 6)$. ${ }^{3}$ Throughout our results, the acronym "PTSD" is used when referring Sample 1, for whom such diagnoses
}

related cognitions Scale (Raylu \& Oei, 2004). This four-item subscale asks participants to respond using a scale of 1 (strongly disagree) to 7 (strongly agree) to items such as "Gambling makes me happier" and "Gambling makes things seem better." For the present work, responses were averaged.

Gambling motives. In Sample 1, coping motivations for gambling were assessed using the Negative Emotions subscale of the Inventory of Gambling Situations (Turner \& Littman-Sharp, 2006; Turner, Littman-Sharp, Toneatto, Liu, \& Ferentzy, 2013). This 8-item scale asks participants to report how often they gamble heavily in response to certain situations. Responses are rated on a scale of 1 (almost never/never gambled heavily in that situation) to 4 (almost always gambled heavily in that situation). This particular subscale has been used as an indicator of coping as a primary motivation for gambling in prior research (Stewart, Zack, Collins, \& Klein, 2008).

In Sample 2, coping motivation for gambling was assessed via the Coping subscale of the Gambling Motives Questionnaire (Stewart \& Zack, 2008). This five-item scale requires participants to report how often they gamble for mood regulation on a scale of 1 (almost never/never) to 4 (almost always).

PTSD and Post-Traumatic Stress. ${ }^{3}$ In Sample 1, PTSD was assessed via the presence $(n=$ $140)$ or absence $(n=189)$ of a PTSD diagnosis on the veteran's medical record, in conjunction with a current evaluation of symptoms and presentation. Upon entry into the treatment program, patient health records and previous diagnostic history were independently reviewed by a staff psychologist and a staff psychiatrist, and the patient's current presentation and symptoms were also evaluated. When both staff members were in agreement that the pre-existing diagnosis of PTSD was accurate (e.g., depending on the year of admission, that either DSMIV-TR or DSM- 5 criteria had been met) and current, the presence of this diagnosis was recorded in the veteran's admission packet alongside the previously described measures. In the event of a historical diagnosis of PTSD but the absence of current symptoms, then the diagnosis was not recorded.

were confirmed, whereas the term "post-traumatic stress" is used when referring to Sample 2, for whom scale scores may represent PTSD or subclinical symptoms of traumatic stress. 
In Sample 2, post-traumatic stress was assessed via two methods. First, participants completed the Life Events Checklist (Gray, Litz, Hsu, \& Lombardo, 2004). This measure requires participants to record their level of experience (e.g., "it happened to you personally," "you witnessed it happen to somebody else," or "you learned about it happening to a close family member or close friend") with 17 different types of traumatic events. For the purpose of the present work, we focused only on participants who had first-hand experience with such traumas (e.g., directly experienced or witnessed occurring). In our sample, $85.6 \%$ of participants $(n=589)$ reported either directly experiencing or personally witnessing one of the specified traumatic events, which is consistent with national prevalence rates (e.g., 89\%, Kilpatrick et al., 2013). Participants not reporting first-hand experience or witnessing of a trauma were excluded from all analyses.

To measure levels of post-traumatic stress in Sample 2, we administered the PTSD ChecklistCivilian version (PCL-C; Ruggiero, Ben, Scotti, \& Rabalais, 2003). Participants were directed to think of the single most traumatic event they had experienced in their lifetimes, and, with that trauma in mind, complete the questionnaire. Participants responded using a scale of 1 (not at all) to 5 (extremely) to indicate the extent to which PTSD symptoms had bothered them in the past month. For the present study, responses were summed.

Neuroticism. In Sample 1, neuroticism was measured using the neuroticism subscale of the Revised NEO Personality Inventory (NEO-PI-R; Costa \& MacCrae, 1992). All six facet subscales of the neuroticism domain were used as control variables (Anxiety, Angry Hostility, Depression, Self-Consciousness, Immoderation, and Vulnerability).

In Sample 2, neuroticism was measured using the International Personality Inventory Pool NEO 120 (IPIP-NEO-120; Maples, Guan, Carter, \& Miller, 2014), which is an open-source inventory that parallels the NEO-PI-R closely. All six subscales of the neuroticism facet were used as control variables (Anxiety, Anger, Depression, Self-Consciousness, Immoderation, and Vulnerability).

\section{Analytic Plan}

Descriptive statistics were computed for all measures in both samples. These statistics are available in Table 1. In both samples, all measures demonstrated acceptable to excellent internal consistency.
In our sample of inpatient veterans, independent samples $t$ tests were conducted comparing individuals with PTSD diagnoses $(n=$ $140)$ to those without such diagnoses $(n=189)$ on key variables (gambling severity, gambling related cognitions, and coping motivations). Post hoc power analyses conducted using the "pwr" package (Champely et al., 2017) for R statistical software indicated that our sample was sufficiently sized to reliably detect effect sizes of Cohen's $d \geq .40$ (i.e., power $=.95$, alpha $=.05$, hypothesis $=$ two sided).

In both samples, correlations were computed between PTSD/post-traumatic stress, positive gambling expectancies, and coping motivations for gambling.

Elements of the SEM constructed for our sample of inpatient veterans were defined as follows: The latent variable Coping Motivation was defined by the observed variables of the Negative Emotions subscale of the IGS. In both samples, the latent variable Positive Gambling Expectancies was defined by the items of the Positive Expectation subscale of the GRCS. The latent variable Neuroticism was defined by the observed neuroticism subscale scores of the NEO-PI-R. Finally, the observed variables PTSD and Gambling Symptom Severity were included, defined by the presence/absence of a PTSD diagnosis and sum scores on the SOGS, respectively.

In our online sample of gambling adults, the latent variable Coping Motivation was defined by the observed variables of the items on the Coping subscale of the GMQ. As previously mentioned, in both samples, the latent variable Positive Gambling Expectancies was defined by the items of the Positive Expectation subscale of the GRCS. Additionally, the latent variable Neuroticism was defined by the observed neuroticism subscale scores of the NEOIPIP-120. Finally, the observed variables PostTraumatic Stress, Traumatic Events Sum, and Gambling Symptom Severity were included, defined by participant sum-scores on the PCL-C, LEC, and SOGS, respectively.

As summarized in Figures 1 and 2, in both samples, SEMs were defined in which PTSD (Sample 1) or Post Traumatic Stress (Sample 2) predicted Coping Motivation, both directly and indirectly through Positive Gambling Expectancies. Gambling Symptom Severity was included as a predictor of gambling related variables (e.g., Coping Motivation, and Positive Gambling Expectancies) and a covariate of PTSD or Post-Traumatic Stress. Finally, Neuroticism was included in both models as a covariate of other exogenous variables (i.e., Post- 
Traumatic Stress, Gambling Symptom Severity) and a predictor of key endogenous variables (e.g., Coping Motivation, and Positive Gambling Expectancies). Results

Descriptive statistics for both samples are available in Table 1.

Sample 1 Results. In our sample of treatment-seeking veterans, using the more conservative cutoff score of 8 on the SOGS, as recommended for clinical settings (Goodie et al., $2013), 93.4 \%(n=310)$ of the sample scored in the probable GD range. These findings are consistent with the nature of the sample as treatment seeking for GD.

Furthermore, in this sample, independent samples $t$ tests revealed that those with a PTSD diagnosis, relative to those without such a diagnosis, demonstrated significantly greater coping motivations for gambling behavior and greater positive expectancies for gambling (see Table 2). However, both of these differences were in the smallto-moderate range by conventional standards (Cohen, 1992). There were no significant differences observed between either group for gambling symptom severity.

Pearson correlations revealed that coping motivations for gambling were positively correlated with gambling symptom severity and with positive expectancies for gambling. However, gambling symptom severity itself was not significantly linked to positive expectancies for gambling. These results are summarized in Table 3.

Results from SEM analyses (See Figure 1) indicated adequate fit in this sample, $(\chi 2(201)=$ $319.23, p<.01, \mathrm{CFI}=.959$, RMSEA $=.042$, $\mathrm{SRMR}=$ .039). Neuroticism, positive gambling expectancies, PTSD, and gambling symptom severity all emerged as significant and positive predictors of coping motivations for gambling, accounting for substantial amounts of variance in such motivation $\left(R^{2}=.385\right)$. Additionally, consistent with hypothesized relationships, PTSD was positively associated with positive gambling expectancies, although gambling symptom severity and neuroticism were not.

\footnotetext{
${ }^{4}$ Using more liberal cutoff scores (e.g., 8 for clinical samples, as specified by Goodie et al., 2013; or 5 as specified in the SOGS original development Lesieur \& Blume, 1987) a larger proportion screened positive for possible GD (cutoff $=5, n=136,23 \%$; cutoff $=8, n=68$, $12 \%)$.

${ }^{5}$ We additionally tested a model in which the PCL total score was replaced by a dichotomous indicator of PTSD
}

Neuroticism was positively associated with PTSD, but not with gambling symptom severity. The indirect effect of PTSD on coping motivation through positive gambling expectancies was significant (indirect effect $=.036 ; \mathrm{p}=.035$ ), as was the total effect of PTSD (both direct and indirect) on coping motivation (effect $=.167, \mathrm{p}=.002$ ).

Sample 2 Results. In our online convenience sample of gambling adults, using conservative scoring recommended for non-clinical screening with the SOGS (cutoff score of 12; Goodie et al., 2013), only 5.2\% $(n=30)$ of participants in our online sample screened positive for probable GD, suggesting that participants in this sample were largely not experiencing problems related to their gambling behaviors. ${ }^{4}$ Furthermore, when analyzing results on the PCL-C, using the recommended cutoff of 38 (Weathers et al., 2013), we found that $36 \%$ of our sample met criteria for likely PTSD. Using a more conservative cut scores of 44 and 50 (Ruggiero et al., 2003) revealed lower base rates $(23 \%$ and $16 \%$ respectively). Although this is a very high prevalence rate, it is also consistent with previous studies of MTurk populations (e.g., 19\%, Price \& van Stolk-Cooke, 2015; 33\%, Seligowski \& Orcutt, 2016)

Pearson correlations (See Table 3 ) revealed that post-traumatic stress was positively related to positive gambling expectancies and coping motivations for gambling. Additionally, in this sample, coping motivation was also positively related to positive gambling expectancies and gambling symptom severity, although the observed effect was larger (in both cases) for participants in Sample 2. However, whereas gambling symptom severity was not significantly related to positive expectancies in Sample 1, symptom severity was positively related to both post-traumatic stress and positive expectancies in Sample 2.

Results from our SEM revealed an adequate fit for our specified model; $\chi^{2}(125)=391.89, p<$ $.01, \mathrm{CFI}=.949, \mathrm{RMSEA}=.061, \mathrm{SRMR}=.046{ }^{5}$ Consistent with Sample 1, positive gambling expectancies, post-traumatic stress, and gambling symptom severity all emerged as significant and

status based on a PCL cut score of 44 (Ruggiero et al., 2003), to make the analysis more parallel with our inpatient sample. The fit of this alternative model was virtually identical $(X 2(125)=381.46, p<.01, \mathrm{CFI}=.950$, RMSEA $=.060$, SRMR $=.047$ ) to the reported model, with no substantive differences in sign or significance for any specified paths. Given these similarities, we have only reported the originally described model. 
positive predictors of coping motivations for gambling (see Figure 2), accounting for substantial amounts of variance in such motivation $\left(R^{2}=.652\right)$. However, in contrast with Sample 1, neuroticism was not related to coping motivations for gambling. Furthermore, in this sample, post-traumatic stress was not significantly associated with positive gambling expectancies, but gambling symptom severity did demonstrate a positive predictive relationship with positive gambling expectancies. Finally, the indirect effect of post-traumatic stress on coping motivations for gambling did not reach statistical significance (indirect effect estimate $=$ $.056, p=.114$ ), although the total effect of posttraumatic stress on coping motivations (both directly and indirectly) was positive and significant (total effect estimate $=.216, p<.001$ ).

\section{Discussion}

We examined the relationships among gambling disorder, positive gambling expectancies, motivations for gambling behaviors, and symptoms of PTSD. Using both a clinical sample of veterans with GD and an online convenience sample of gambling adults who had experienced trauma, we tested the hypothesis that symptoms of PTSD are related to coping motivations for gambling behaviors via positive gambling expectancies. Below, we review our findings and discuss the implications of the present work.

\section{Gambling and Post Traumatic Stress Disorder}

In a clinical sample of treatment seeking veterans with confirmed diagnoses of GD, $42.5 \%$ of participants had confirmed diagnoses of PTSD. Although not a nationally representative epidemiological sample, such a rate of PTSD is considerably higher than the general base rate for PTSD among veterans, which ranges from roughly $10 \%$ for Gulf War veterans (Kang, Natelson, Mahan, Lee, \& Murphy, 2003) to $23 \%$ for OEF/OIF veterans (Fulton et al., 2015) to $30 \%$ for Vietnam veterans (Kulka et al., 1990). However, this rate is notably lower than the base rate for OEF/OIF veterans who have diagnosed substance use disorders $(63 \%$, Seal et al., 2011). Even so, there were no significant differences between those with PTSD and those without in terms of gambling symptom severity (as assessed by the SOGS). This is possibly due to the overall severity of gambling symptoms in this sample in general (i.e., a sample of inpatients seeking treatment for GD). In our online convenience sample of gambling adults, for which there was greater variability for both gambling behavior and posttraumatic stress symptoms, there were clear and moderate associations between post-traumatic stress symptoms and gambling symptom severity. These results are consistent with prior works (Ledgerwood \& Milosevic, 2015; Ledgerwood \& Petry, 2006), indicating cross-sectional associations between posttraumatic stress and GD.

Regarding specific gambling-related cognitions and motivations, our results were partially consistent with our hypotheses. Much like recent findings in a community sample (Ledgerwood \& Milosevic, 2015), results from both our inpatient sample of treatment-seeking veterans and our online convenience sample of gambling adults indicated that PTSD (Sample 1) and post-traumatic stress (Sample 2) were linked to coping motivations for gambling. In our clinical sample, among those participants with PTSD, positive expectancies for gambling and coping motivations for gambling were both elevated, relative to those participants without PTSD. Additionally, in our online sample of gambling adults, correlations between post-traumatic stress and coping motivations for gambling were apparent, though small-tomoderate in size. These associations were also observed in the SEM analyses, even when trait neuroticism and gambling symptom severity were included in the model as covariates. Consistent with prior work on the topic (Ledgerwood \& Milosevic, 2015), these findings bolster the conclusion that symptoms of PTSD are particularly associated with the use of gambling behaviors to manage or alleviate negative affect.

Moving further, in our online sample of gambling adults, correlations between positive gambling expectancies and both coping motivations for gambling and post-traumatic stress were consistently positive, although often small-tomoderate in size. Although these initial patterns of correlations were consistent with our hypotheses, subsequent SEM analyses revealed different patterns of associations and significance between our samples. Among treatment seeking veterans with confirmed GD, there was a clear cross-sectional pathway from PTSD to positive gambling expectancies to coping motivations for gambling, with clear indirect and direct effects of PTSD on coping motivations. However, among our online sample of largely nonGD individuals, such a pathway did not emerge. Specifically, although post-traumatic stress and positive gambling expectancies were individually related to coping motivations for gambling behavior, there was not a significant association between posttraumatic stress and positive gambling expectancies themselves. 


\section{Implications}

Collectively, the present work underscores prior works examining PTSD and GD. Chiefly, as has been established in prior literature, there are clear and important links between PTSD and GD. In both clinical samples of individuals with GD and an online sample of gamblers (both with and without GD), the links between GD and symptoms of PTSD were clear and consistent. Symptoms of PTSD seem to be associated with greater severity of gambling symptoms, greater positive expectancies for gambling behaviors, and greater coping motivations for gambling.

Given these findings, the roles that positive gambling expectancies play in the context of GD for individuals with symptoms of PTSD merit further investigation by gambling researchers and greater consideration by clinicians who provide care to those with GD. Building on numerous past works that have noted an emotionally vulnerable gambling subtype that is particularly likely to use gambling to cope with negative affect (e.g., Ledgerwood \& Petry, 2010; Milosevic \& Ledgerwood, 2010), the expectation that gambling will provide the gambler with a positive experience might be critical to understanding the "emotionally vulnerable" problem gambling pathway. However, based on our findings, it is possible that this only holds true for more extreme cases, such as individuals with a diagnosis of PTSD who are in residential care, as there was no significant association between post-traumatic stress and positive gambling expectancies in the online convenience sample of gambling adults in our full models. Researchers should further explore the incidence of positive gambling expectancies among individuals with a broad array of mental health conditions to identify which clinical profiles are most likely to predispose an individual towards positive gambling expectancies and, in turn, GD.

Given the relatively high comorbidity between PTSD and GD and the unique motivations for gambling associated with PTSD, clinicians should consider tailoring treatment for individuals with both GD and PTSD to address the specific motivations that they may have for gambling. Specifically, interventions that can challenge individuals with GD to evaluate the likelihood that gambling experiences will, in fact, be positive, might be an especially useful approach - and especially so for individuals with high levels of neuroticism or traumatic stress. While it is too soon to conclude definitively that positive gambling expectancies serve as a causal mediator between mental distress and coping motivations, findings from the present work indicate that this is a possibility worth further consideration.

\section{Limitations}

Methodological limitations of the current study merit consideration for evaluating the impact of our findings. Chiefly, the present work was fully cross-sectional in nature. The directionality of predictions in the specified SEM analyses should not be interpreted as implying causality, as correlational study designs prevent such conclusions. Similarly, although we did compute indirect effects, whether or not such effects represent true mediation is not indicated by our findings. At present, the strongest conclusion that can be made from the patterns of findings is that there are distinct relationships between symptoms of PTSD and coping motivations for gambling, and it is plausible that these links are at least partially accounted for by positive gambling expectancies. Future research should explore these hypothesized relationships using longitudinal or experimental designs that are better suited to determine causality.

We would also note that symptoms of PTSD were measured extremely differently between the two samples, with our inpatient sample of veterans relying on a dichotomous categorization based on formal clinician diagnosis and our online convenience sample of gambling adults relying scale data among individuals with self-reported exposure to trauma. Future work, particularly in clinical samples, should seek to replicate these findings with scale data among those with PTSD diagnoses. The many differences between our samples - U.S. Armed Forces veterans vs. a general sample of adults in the U.S. for whom veteran status was unknown, diagnosed gambling disorder vs. subclinical gambling behavior, treatment seeking sample vs. a sample for which treatment seeking was not assessed-make it difficult to draw firm conclusions about the causes of the differences in our findings. We also note that the uniqueness of the GD/PTSD comorbidity needs to be tested in comparison to comorbidities between PTSD and substance use disorders and in comparison to comorbidities between GD and other psychiatric problems. Although the present work posits that the links between PTSD and GD may be unique in comparison to other comorbidities with either disorder, future research should attempt to test this directly.

Finally, we also note that our use of measures of gambling motivations may be a source of potential confounding in interpreting our findings. Specifically, the Negative Affect subscale of the IGS 
requires participants to indicate how often they gambled heavily in response to specific situations, whereas the Coping Motivations Subscale of the GMQ specifically assesses the frequency with which participants gambled to reduce negative affect. Although similar in form or content, only the GMQ specifically asks if the goal of gambling is to reduce negative affect. Even so, our use of the IGS as an indicator of gambling motivations is consistent with prior work (Stewart et al., 2008), including validation studies of the IGS, which noted that the Negative Affect subscale was likely related to the desire to use gambling to cope with negative mood (Turner et al., 2013).

\section{Conclusions}

Across two samples — one involving veterans of the U.S. Armed Forces in a residential treatment program for GD and one involving an online sample of gambling adults - we found consistent and positive associations between PTSD (as well as symptoms of post-traumatic stress) and coping motivations for gambling. Additionally, we also found links between PTSD and positive gambling expectancies. Although results differed by sample, in both samples, positive gambling expectancies were related to coping motivations for gambling, indicating that positive gambling expectancies merit further attention in research on GD and its comorbidity with other mental health disorders

\section{Acknolwedgements}

We gratefully acknowledge the support of the National Center for Responsible Gaming in the form of a Pilot Grant awarded to the first author of this manuscript. The content of this manuscript does not necessarily reflect the views of the funding agencies and reflects the views of the authors.

\section{References}

Biddle, D., Hawthorne, G., Forbes, D., \& Coman, G. (2005). Problem gambling in Australian PTSD treatment-seeking veterans. Journal of Traumatic Stress, 18, 759-767. https://doi.org/10.1002/jts.20084

Brady, K. T., \& Sinha, R. (2005). Co-occurring mental and substance use disorders: The neurobiological effects of chronic stress. American Journal of Psychiatry, 162, 14831493.

https://doi.org/10.1176/appi.ajp.162.8.1483
Champely, S., Ekstrom, C., Dalgaard, P., Gill, J., Weibelzahl, S., Anandkumar, A., ... De Rosario, M. H. (2017). Package 'pwr.'

Chandler, J., \& Shapiro, D. (2016). Conducting clinical research using crowdsourced convenience samples. Annual Review of Clinical Psychology, 12, 53-81. https://doi.org/10.1146/annurev-clinpsy021815-093623

Chou, K.-L., \& Afifi, T. O. (2011). Disordered (pathologic or problem) gambling and axis $i$ psychiatric disorders: Results from the national epidemiologic survey on alcohol and related conditions. American Journal of Epidemiology, 173, 1289-1297. https://doi.org/10.1093/aje/kwr017

Cohen, J. (1992). A power primer. Psychological Bulletin, 112, 155-159.

Costa, P. T., \& MacCrae, R. R. (1992). Revised NEO personality inventory (NEO PI-R) and NEO five-factor inventory (NEO-FFI):

Professional manual. Psychological Assessment Resources, Incorporated.

Emond, M. S., \& Marmurek, H. H. (2010). Gambling related cognitions mediate the association between thinking style and problem gambling severity. Journal of Gambling Studies, 26, 257-267.

Fauth-Bühler, M., Mann, K., \& Potenza, M. N. (2017). Pathological gambling: a review of the neurobiological evidence relevant for its classification as an addictive disorder. Addiction Biology, 22, 885-897.

Fulton, J. J., Calhoun, P. S., Wagner, H. R., Schry, A. R., Hair, L. P., Feeling, N., ... Beckham, J. C. (2015). The prevalence of posttraumatic stress disorder in Operation Enduring Freedom/Operation Iraqi Freedom (OEF/OIF) Veterans: A meta-analysis. Journal of Anxiety Disorders, 31, 98-107. https://doi.org/10.1016/j.janxdis.2015.02.003

Goodie, A. S., MacKillop, J., Miller, J. D., Fortune, E. E., Maples, J., Lance, C. E., \& Campbell, W. K. (2013). Evaluating the South Oaks Gambling Screen with DSM-IV and DSM-5 criteria: Results from a diverse community sample of gamblers. Assessment, 20, 523531. https://doi.org/10.1177/1073191113500522

Grant, J. E., Potenza, M. N., Weinstein, A., \& Gorelick, D. A. (2010). Introduction to behavioral addictions. The American Journal of Drug and Alcohol Abuse, 36, 233-241. 
https://doi.org/10.3109/00952990.2010.4918 84

Gray, M. J., Litz, B. T., Hsu, J. L., \& Lombardo, T. W. (2004). Psychometric properties of the Life Events Checklist. Assessment, 11, 330 341. https://doi.org/10.1177/1073191104269954

Kang, H. K., Natelson, B. H., Mahan, C. M., Lee, K. Y., \& Murphy, F. M. (2003). Post-traumatic stress disorder and chronic fatigue syndrome-like illness among Gulf War veterans: a population-based survey of 30,000 veterans. American Journal of Epidemiology, 157, 141-148.

Kessler, R. C., Hwang, I., LaBrie, R., Petukhova, M., Sampson, N. A., Winters, K. C., \& Shaffer, H. J. (2008). DSM-IV pathological gambling in the National Comorbidity Survey Replication. Psychological Medicine, 38. https://doi.org/10.1017/S0033291708002900

Khantzian, E. J. (1997). The self-medication hypothesis of substance use disorders: a reconsideration and recent applications. Harvard Review of Psychiatry, 4, 231-244. https://doi.org/10.3109/10673229709030550

Kilpatrick, D. G., Resnick, H. S., Milanak, M. E., Miller, M. W., Keyes, K. M., \& Friedman, M. J. (2013). National Estimates of Exposure to Traumatic Events and PTSD Prevalence Using DSM-IV and DSM-5 Criteria. Journal of Traumatic Stress, 26, 537-547. https://doi.org/10.1002/jts.21848

Kim, H. S., \& Hodgins, D. C. (2017). Reliability and validity of data obtained from alcohol, cannabis, and gambling populations on Amazon's Mechanical Turk. Psychology of Addictive Behaviors, 31, 85-94. https://doi.org/10.1037/adb0000219

Kulka, R. A., Schlenger, W. E., Fairbank, J. A., Hough, R. L., Jordan, B. K., Marmar, C. R., \& Weiss, D. S. (1990). Trauma and the Vietnam war generation: Report of findings from the National Vietnam Veterans Readjustment Study. Brunner/Mazel.

Ledgerwood, D. M., \& Milosevic, A. (2015). Clinical and personality characteristics associated with post traumatic stress disorder in problem and pathological gamblers recruited from the community. Journal of Gambling Studies, 31, 501-512.

Ledgerwood, D. M., \& Petry, N. M. (2006). Posttraumatic stress disorder symptoms in treatment-seeking pathological gamblers.
Journal of Traumatic Stress, 19, 411-416. https://doi.org/10.1002/jts.20123

Ledgerwood, D. M., \& Petry, N. M. (2010). Subtyping pathological gamblers based on impulsivity, depression, and anxiety. Psychology of Addictive Behaviors, 24, 680 688. https://doi.org/10.1037/a0019906

Lesieur, H. R., \& Blume, S. B. (1987). The South Oaks Gambling Screen (SOGS): A new instrument for the identification of pathological gamblers. American Journal of Psychiatry, 144.

Litman, L., Robinson, J., \& Abberbock, T. (2017). TurkPrime.com: A versatile crowdsourcing data acquisition platform for the behavioral sciences. Behavior Research Methods, 49, 433-442. https://doi.org/10.3758/s13428$016-0727-z$

Maples, J. L., Guan, L., Carter, N. T., \& Miller, J. D. (2014). A test of the International Personality Item Pool representation of the Revised NEO Personality Inventory and development of a 120-item IPIP-based measure of the five-factor model. Psychological Assessment, 26, 1070.

Mathieu, S., Barrault, S., Brunault, P., \& Varescon, I. (2017). Gambling motives: Do they explain cognitive distortions in male poker gamblers? Journal of Gambling Studies, 113. https://doi.org/10.1007/s10899-0179700-8

Miller, N. V., \& Currie, S. R. (2008). A Canadian population level analysis of the roles of irrational gambling cognitions and risky gambling practices as correlates of gambling intensity and pathological gambling. Journal of Gambling Studies, 24, 257-274.

Milosevic, A., \& Ledgerwood, D. M. (2010). The subtyping of pathological gambling: A comprehensive review. Clinical Psychology Review, 30, 988-998. https://doi.org/10.1016/j.cpr.2010.06.013

Najavits, L. M. (2010). Treatment utilization of pathological gamblers with and without PTSD. Journal of Gambling Studies, 26, 583-592. https://doi.org/10.1007/s10899010-9179-z

Najavits, L. M., Meyer, T., Johnson, K. M., \& Korn, D. (2011). Pathological gambling and posttraumatic stress disorder: A study of the co-morbidity versus each alone. Journal of Gambling Studies, 27, 663-683. https://doi.org/10.1007/s10899-010-9230-0 
Najavits, L. M., Sullivan, T. P., Schmitz, M., Weiss, R. D., \& Lee, C. S. N. (2004). Treatment utilization by women with PTSD and substance dependence. The American Journal on Addictions, 13, 215-224. https://doi.org/10.1080/10550490490459889

Nower, L., Eyrich-Garg, K. M., Pollio, D. E., \& North, C. S. (2015). Problem gambling and homelessness: Results from an epidemiologic study. Journal of Gambling Studies, 31, 533-545. https://doi.org/10.1007/s10899-013-9435-0

Ouimette, P., \& Brown, P. J. (Eds.). (2003). Trauma and substance abuse: Causes, consequences, and treatment of comorbid disorders. Trauma and Substance Abuse: Causes, Consequences, and Treatment of Comorbid Disorders., xiii, 315-xiii, 315. https://doi.org/10.1037/10460-000

Parhami, I., Mojtabai, R., Rosenthal, R. J., Afifi, T. O., \& Fong, T. W. (2014). Gambling and the onset of comorbid mental disorders: A longitudinal study evaluating severity and specific symptoms. Journal of Psychiatric Practice ${ }^{\circledR}, 20,207$. https://doi.org/10.1097/01.pra.0000450320.9 $8988.7 \mathrm{c}$

Petry, N. M. (2005). Pathological gambling: Etiology, comorbidity, and treatment. Pathological Gambling: Etiology, Comorbidity, and Treatment., x, 417-x, 417. https://doi.org/10.1037/10894-000

Petry, N. M., Blanco, C., Jin, C., \& Grant, B. F. (2014). Concordance between gambling disorder diagnoses in the DSM-IV and DSM-5; Results from the National Epidemiological Survey of Alcohol and Related Disorders. Psychology of Addictive Behaviors : Journal of the Society of Psychologists in Addictive Behaviors, 28, 586-591. https://doi.org/10.1037/a0034661

Potenza, M. N., Maciejewski, P. K., \& Mazure, C. M. (2006). A gender-based examination of pastyear recreational gamblers. Journal of Gambling Studies, 22, 41-64. https://doi.org/10.1007/s10899-005-9002-4

Price, M., \& van Stolk-Cooke, K. (2015). Examination of the interrelations between the factors of PTSD, major depression, and generalized anxiety disorder in a heterogeneous trauma-exposed sample using DSM 5 criteria. Journal of Affective
Disorders, 186, 149-155.

https://doi.org/10.1016/j.jad.2015.06.012

Raylu, N., \& Oei, T. P. S. (2004). The Gambling

Related Cognitions Scale (GRCS):

Development, confirmatory factor validation and psychometric properties. Addiction, 99, 757-769. https://doi.org/10.1111/j.13600443.2004.00753.x

Reilly, C., \& Smith, N. (2013). The evolving definition of pathological gambling in the DSM-5. National Center for Responsible Gaming, 1-6.

Ruggiero, K. J., Ben, K. D., Scotti, J. R., \& Rabalais, A. E. (2003). Psychometric properties of the PTSD Checklist - Civilian version. Journal of Traumatic Stress, 16, 495-502.

Scherrer, J. F., Slutske, W. S., Xian, H., Waterman, B., Shah, K. R., Volberg, R., \& Eisen, S. A. (2007). Factors associated with pathological gambling at 10-year follow-up in a national sample of middle-aged men. Addiction, 102, 970-978.

Scherrer, J. F., Xian, H., Kapp, J. M. K., Waterman, B., Shah, K. R., Volberg, R., \& Eisen, S. A. (2007). Association between exposure to childhood and lifetime traumatic events and lifetime pathological gambling in a twin cohort. The Journal of Nervous and Mental Disease, 195, 72-78.

Seal, K. H., Cohen, G., Waldrop, A., Cohen, B. E., Maguen, S., \& Ren, L. (2011). Substance use disorders in Iraq and Afghanistan veterans in VA healthcare, 2001-2010: Implications for screening, diagnosis and treatment. Drug \& Alcohol Dependence, 116, 93-101.

Seligowski, A. V., \& Orcutt, H. K. (2016). Support for the 7-factor hybrid model of PTSD in a community sample. Psychological Trauma: Theory, Research, Practice, and Policy, 8 , 218-221. https://doi.org/10.1037/tra0000104

Shapiro, D. N., Chandler, J., \& Mueller, P. A. (2013). Using Mechanical Turk to study clinical populations. Clinical Psychological Science, 1, 213-220.

Stewart, S. H., \& Zack, M. (2008). Development and psychometric evaluation of a threedimensional Gambling Motives Questionnaire. Addiction, 103, 1110-1117.

Stewart, S. H., Zack, M., Collins, P., \& Klein, R. M. (2008). Subtyping pathological gamblers on the basis of affective motivations for gambling: Relations to gambling problems, drinking problems, and affective motivations 
for drinking. Psychology of Addictive

Behaviors, 22, 257-268.

https://doi.org/10.1037/0893-164X.22.2.257

Stinchfield, R., McCready, J., Turner, N. E., Jimenez-

Murcia, S., Petry, N. M., Grant, J., ...

Winters, K. C. (2016). Reliability, validity, and classification accuracy of the DSM-5 diagnostic criteria for gambling disorder and comparison to DSM-IV. Journal of Gambling Studies, 32, 905-922. https://doi.org/10.1007/s10899-015-9573-7

Taylor, K. M., \& Sharpe, L. (2008). Trauma and post-traumatic stress disorder among homeless adults in Sydney. Australian \& New Zealand Journal of Psychiatry, 42, 206-213. https://doi.org/10.1080/00048670701827218

Toneatto, T., \& Pillai, S. (2016). Mood and anxiety disorders are the most prevalent psychiatric disorders among pathological and recovered gamblers. International Journal of Mental Health and Addiction, 14, 217-227. https://doi.org/10.1007/s11469-016-9647-5

Turner, N. E., \& Littman-Sharp, N. (2006). Inventory of Gambling Situations user's guide.

Toronto, ON: Centre for Addictions and Mental Health.

Turner, N. E., Littman-Sharp, N., Toneatto, T., Liu, E., \& Ferentzy, P. (2013). Centre for Addiction and Mental Health Inventory of Gambling Situations: Evaluation of the factor structure, reliability, and external correlations. International Journal of Mental Health and Addiction, 11, 526-545. https://doi.org/10.1007/s11469-013-9446-1

Weathers, F. W., Litz, B. T., Keane, T. M., Palmieri, P. A., Marx, B. P., \& Schnurr, P. P. (2013). The PTSD checklist for DSM-5 (PCL-5). Scale Available from the National Center for PTSD at Www. Ptsd. va. Gov.

Westermeyer, J., Canive, J., Garrard, J., Thuras, P., \& Thompson, J. (2005). Lifetime prevalence of pathological gambling among American Indian and Hispanic american veterans. American Journal of Public Health, 95, 860866.

https://doi.org/10.2105/AJPH.2003.023770 
Table 1

Descriptive statistics for included variables.

\begin{tabular}{|c|c|c|c|c|c|c|c|c|}
\hline & \multicolumn{4}{|c|}{ Sample 1} & \multicolumn{4}{|c|}{ Sample 2} \\
\hline & Range & $M(S D)$ & Skew & $\alpha$ & Range & $M(S D)$ & Skew & $\alpha$ \\
\hline $\begin{array}{l}\text { Post-Traumatic } \\
\text { Stress Checklist }\end{array}$ & - & - & - & - & $17-85$ & $\begin{array}{c}32.58 \\
(15.51)\end{array}$ & 0.94 & .952 \\
\hline $\begin{array}{l}\text { Life Events } \\
\text { Checklist }\end{array}$ & - & - & - & - & $1-27$ & $\begin{array}{c}6.34 \\
(4.45)\end{array}$ & 1.36 & - \\
\hline $\begin{array}{l}\text { South Oaks } \\
\text { Gambling Screen }\end{array}$ & $0-21$ & $\begin{array}{l}14.38 \\
(3.94)\end{array}$ & -1.10 & .952 & $0-21$ & $\begin{array}{c}3.6 \\
(3.34)\end{array}$ & 2.12 & .872 \\
\hline $\begin{array}{l}\text { Inventory of } \\
\text { Gambling } \\
\text { Situations: } \\
\text { Negative } \\
\text { Emotions } \\
\text { Subscale }\end{array}$ & $1-4$ & $\begin{array}{l}3.16 \\
(0.67)\end{array}$ & -0.67 & .908 & - & - & - & - \\
\hline $\begin{array}{l}\text { Gambling Motives } \\
\text { Questionnaire: } \\
\text { Coping Subscale }\end{array}$ & - & - & - & - & $1-4$ & $\begin{array}{c}1.7 \\
(0.68)\end{array}$ & 0.99 & .883 \\
\hline $\begin{array}{l}\text { Gambling-related } \\
\text { cognitions Scale: } \\
\text { Positive } \\
\text { Expectancies } \\
\text { Subscale }\end{array}$ & $1-7$ & $\begin{array}{l}3.92 \\
(1.61)\end{array}$ & -0.20 & .769 & $1-7$ & $\begin{array}{c}3.27 \\
(1.42)\end{array}$ & 0.14 & .861 \\
\hline N1 & $20-80$ & $\begin{array}{l}62.03 \\
(11.87)\end{array}$ & -0.40 & - & $1-5$ & $\begin{array}{c}3.09 \\
(1.13)\end{array}$ & -0.13 & .848 \\
\hline N2 & $20-80$ & $\begin{array}{l}60.68 \\
(12.78)\end{array}$ & -0.00 & - & $1-5$ & $\begin{array}{c}2.77 \\
(1.09)\end{array}$ & 0.11 & .867 \\
\hline N3 & $20-80$ & $\begin{array}{l}70.41 \\
(12.23)\end{array}$ & -0.96 & - & $1-5$ & $\begin{array}{c}2.61 \\
(1.25)\end{array}$ & 0.28 & .915 \\
\hline N4 & $20-80$ & $\begin{array}{l}61.99 \\
(11.49)\end{array}$ & 0.15 & - & $1-5$ & $\begin{array}{c}2.74 \\
(0.99)\end{array}$ & 0.21 & .770 \\
\hline N5 & $20-80$ & $\begin{array}{l}65.09 \\
(10.38)\end{array}$ & -0.02 & - & $1-5$ & $\begin{array}{c}2.96 \\
(0.99)\end{array}$ & -0.07 & .757 \\
\hline N6 & $20-80$ & $\begin{array}{l}67.78 \\
(15.01)\end{array}$ & 0.15 & - & $1-5$ & $\begin{array}{c}2.49 \\
(0.99) \\
\end{array}$ & 0.46 & .822 \\
\hline
\end{tabular}

${ }^{\ddagger}$ In Sample 1, post-traumatic stress was assessed via the presence or absence of a PTSD diagnosis. In Sample 2, PTSS was assessed via scores on the PCL-C among those with trauma exposure.

$\dagger$ In Sample 1, coping motivations for gambling were assessed using the Negative Emotions subscale of the Inventory of Gambling Situations; In Sample 2, coping motivations were assessed using the Coping subscale of the Gambling Motives Questionnaire.

Abbreviations: Sample 1 (NEO-PI-R), Sample 2 (NEO-IPIP-120)

N1 = Anxiety, Anxiety; N2 = Angry Hostility, Anger; N3 = Depression, Depression; N4 = SelfConsciousness, Self-Consciousness; N5 = Impulsivity, Immoderation; N6 = Vulnerability, Vulnerability 
Table 2

Sample 1, Independent t-test comparison of participants with a PTSD diagnosis to those without a PTSD diagnosis.

\begin{tabular}{|c|c|c|c|c|c|c|c|}
\hline & \multicolumn{2}{|c|}{ PTSD Status } & \multirow[b]{2}{*}{$\begin{array}{c}\text { Mean } \\
\text { Difference }\end{array}$} & \multirow[b]{2}{*}{$t$ score } & \multirow[b]{2}{*}{$\mathrm{df}$} & \multirow[b]{2}{*}{$p$} & \multirow[b]{2}{*}{ Cohen's $a$} \\
\hline & $\begin{array}{c}\text { No PTSD } \\
n=189 \\
M(S D)\end{array}$ & $\begin{array}{c}\text { PTSD } \\
n=140 \\
M(S D)\end{array}$ & & & & & \\
\hline $\begin{array}{r}\text { Gambling Symptom } \\
\text { Severity }\end{array}$ & $14.50(4.16)$ & $14.22(3.66)$ & 0.28 & 0.64 & 327 & .524 & 0.07 \\
\hline $\begin{array}{r}\text { Coping Motivations } \\
\text { for Gambling }\end{array}$ & $3.05(0.70)$ & $3.33(0.58)$ & -0.29 & -3.94 & 325 & $<.001$ & -0.44 \\
\hline $\begin{array}{r}\text { Positive Gambling } \\
\text { Expectancies }\end{array}$ & $3.64(1.63)$ & $4.30(1.52)$ & -0.66 & -3.72 & 326 & $<.001$ & -0.41 \\
\hline
\end{tabular}


Table 3

Pearson correlations for included variables.

\begin{tabular}{|c|c|c|c|c|c|c|c|c|}
\hline & \multicolumn{2}{|c|}{$\begin{array}{c}\text { Post-Traumatic Stress } \\
\text { Symptoms }\end{array}$} & \multicolumn{2}{|c|}{$\begin{array}{c}\text { Gambling Symptom } \\
\text { Severity }\end{array}$} & \multicolumn{2}{|c|}{ Coping Motivation $\uparrow$} & \multicolumn{2}{|c|}{ Positive Expectancies } \\
\hline & Sample 1 & Sample 2 & Sample 1 & Sample 2 & Sample 1 & Sample 2 & Sample 1 & Sample 2 \\
\hline $\begin{array}{r}\text { Gambling } \\
\text { Symptom } \\
\text { Severity }\end{array}$ & - & $.317 * *$ & - & - & - & - & - & - \\
\hline $\begin{array}{r}\text { Coping } \\
\text { Motivation } \dagger\end{array}$ & - & $.254 * *$ & $.284 * *$ & $.496 * *$ & - & - & - & - \\
\hline $\begin{array}{r}\text { Positive } \\
\text { Expectancies }\end{array}$ & - & $.170 * *$ & -.073 & $.432 * *$ & $.214^{* *}$ & $.691^{* *}$ & - & - \\
\hline $\begin{array}{r}\text { Traumatic } \\
\text { Event Sum } \\
\text { Score }\end{array}$ & - & $.353 * *$ & - & $.193 * *$ & - & .055 & - & $.124 * *$ \\
\hline $\begin{array}{l}{ }^{*} \text { In Sample 1, po } \\
\text { correlational ana } \\
\dagger \text { In Sample 1, co } \\
\text { In Sample 2, cop } \\
{ }^{*} p<.05,{ }^{*} p\end{array}$ & $\begin{array}{l}\text {-traumatic st } \\
\text { ses. In Sam! } \\
\text { ng motivati } \\
\text { g motivatio } \\
005\end{array}$ & $\begin{array}{l}\text { 2, post-traum } \\
\text { s for gamblin } \\
\text { were assessec }\end{array}$ & $\begin{array}{l}\text { via the preser } \\
\text { ic stress was } \\
\text { vere assessed } \\
\text { sing the Copi }\end{array}$ & $\begin{array}{l}\text { e or absence c } \\
\text { sessed via scc } \\
\text { sing the Nega } \\
\text { g subscale of }\end{array}$ & $\begin{array}{l}\text { a PTSD diagn } \\
\text { s on the PCL- } \\
\text { ve Emotions s } \\
\text { e Gambling M }\end{array}$ & $\begin{array}{l}\text { sis and was th } \\
\text { among those } \\
\text { scale of the In } \\
\text { tives Question }\end{array}$ & $\begin{array}{l}\text { ore omitted } \\
\text { h trauma ex } \\
\text { tory of Gan } \\
\text { e }\end{array}$ & $\begin{array}{l}\text { m } \\
\text { ure. } \\
\text { ng Situations; }\end{array}$ \\
\hline
\end{tabular}




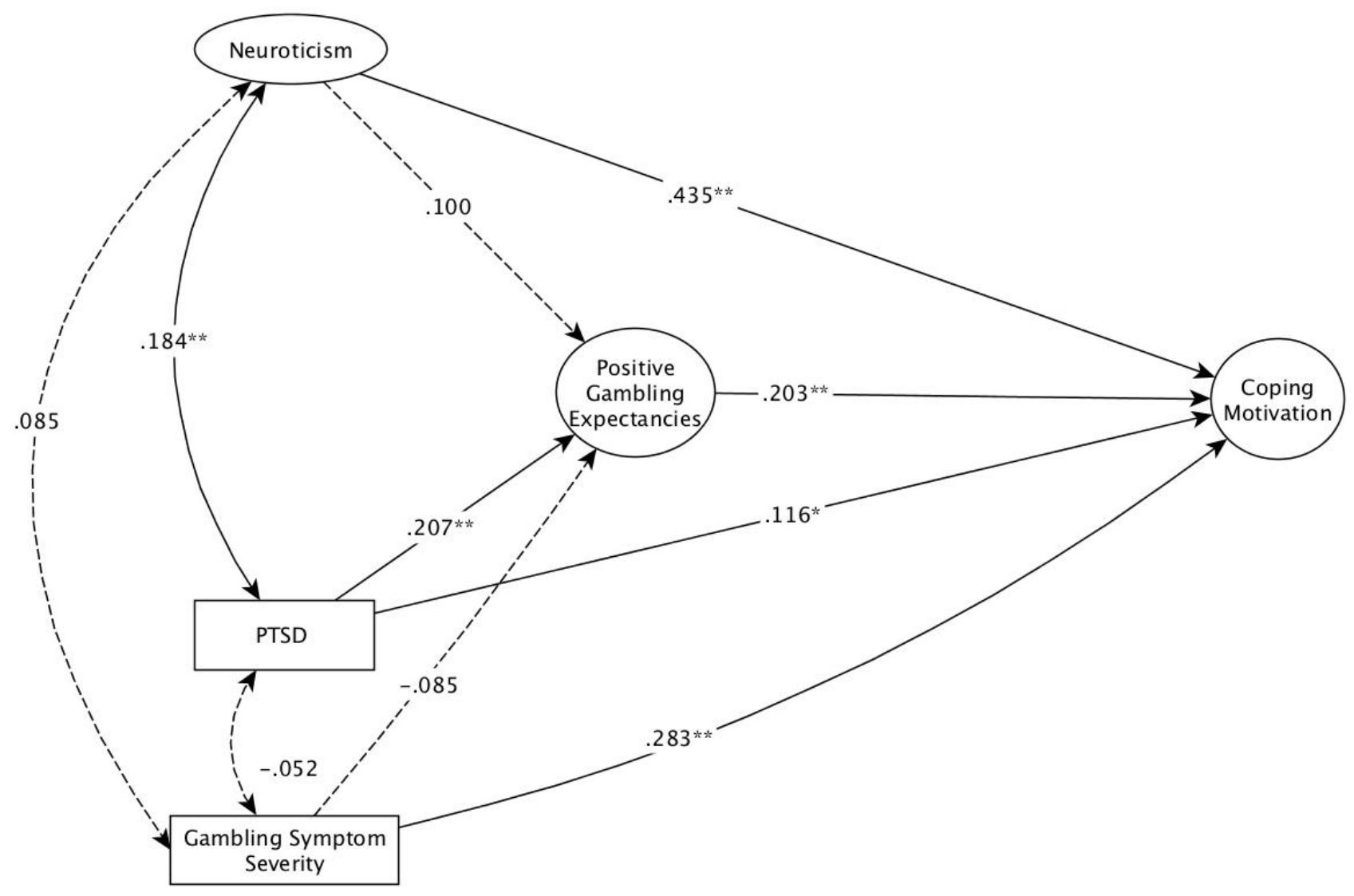

Figure 1. Study 1, Structural Equation Model Predicting Coping Motivations for Gambling.

${ }^{*} p<.05, * * p<.005$. Numbers represent standardized path coefficients. The fit for this model is as follows: $\chi^{2}(201)=319.23, p<.01$, $\mathrm{CFI}=.959, \mathrm{RMSEA}=.042, \mathrm{SRMR}=.039$. The indirect effect of PTSD on Coping Motivation through Positive Gambling Expectancies was significant (indirect effect $=.036 ; p=.035$ ).

Variance accounted for in the present model is as follows: Coping Motivation, $R^{2}=.385$; Positive Gambling Expectancies, $R^{2}=.067$. Observed item indicators for latent variables omitted from diagram to enhance readability. 


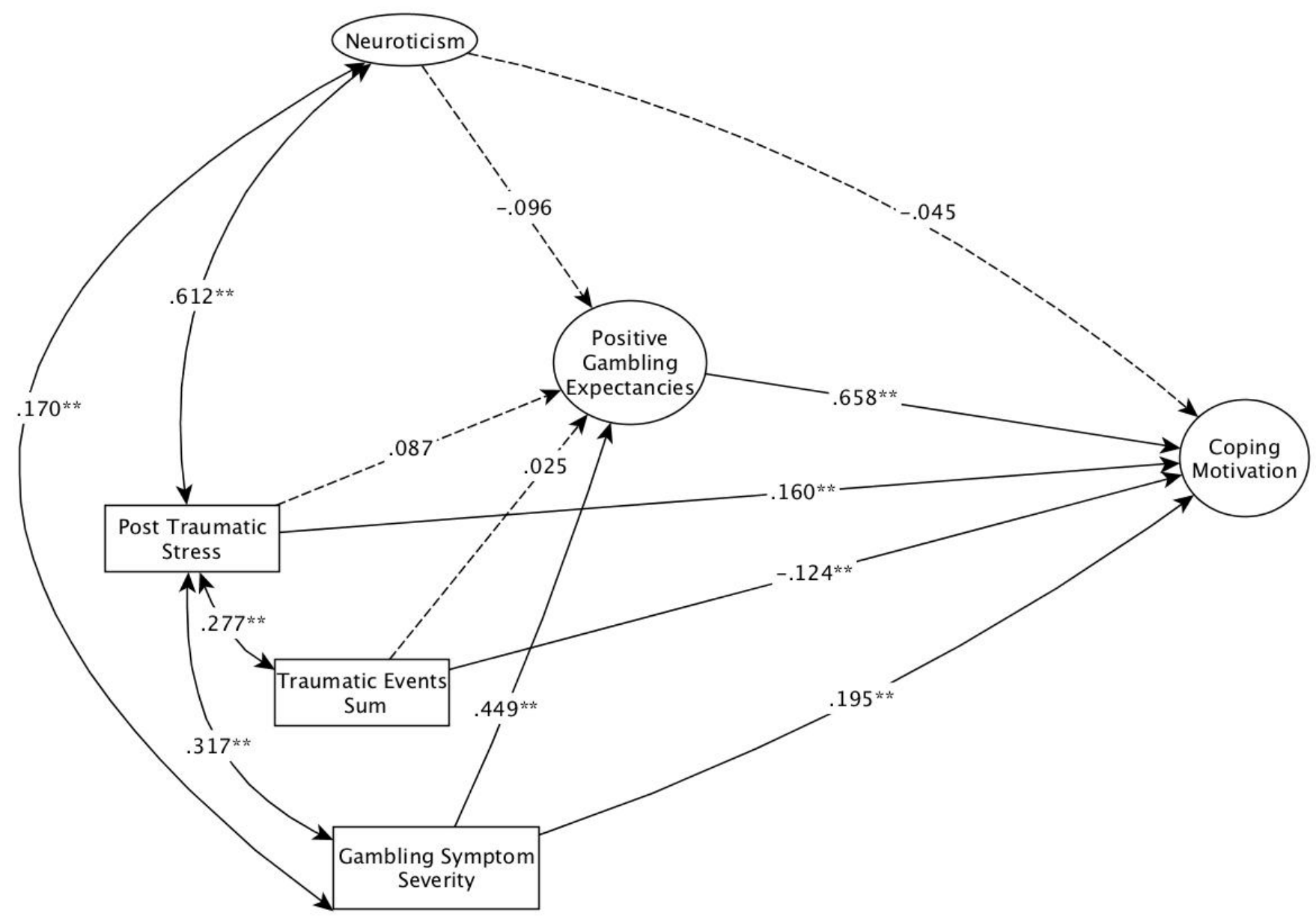

Figure 2. Study 2, Structural Equation Model Predicting Coping Motivations for Gambling.

$p<.05, * * p<.005$. Numbers represent standardized path coefficients. The fit for this model is as follows: $\chi^{2}(125)=391.89, p<.01$, $\mathrm{CFI}=.949, \mathrm{RMSEA}=.061, \mathrm{SRMR}=.046$. The indirect effect of PTSD on Coping Motivation through Positive Gambling

Expectancies was insignificant (indirect effect $=.056 ; p=.114$ ).

Variance accounted for in the present model is as follows: Coping Motivation, $R^{2}=.652$; Positive Gambling Expectancies, $R^{2}=.220$.

Observed item indicators for latent variables omitted from diagram to enhance readability. 